\title{
LA LUCHA POLÍTICA POR LA VIDA CAMPESINA INDÍGENA EN EL CAMPO JURÍDICO. ¿ES POSIBLE DISPUTAR EL SENTIDO DEL DERECHO COMO UNA FORMA DE RESISTENCIA A LA GUBERNAMENTABILIDAD NEOLIBERAL?*
}

\section{THE POLITICAL STRUGGLE FOR INDIGENOUS PEASANT LIFE IN THE LEGAL FIELD. IS IT POSSIBLE TO DISPUTE THE MEANING OF LAW AS A FORM OF RESISTANCE TO NEOLIBERAL GOVERNABILITY?}

\author{
Katia Troncoso Muñoz ${ }^{1}$ \\ ana_katiat@hotmail.com \\ Universidad de Barcelona \\ Barcelona, España \\ DOI: https://doi.org/10.32735/S2735-61752019000116139
}

\begin{abstract}
RESUMEN
Partiendo de las tesis desarrolladas por Michel Foucault respecto del neoliberalismo como nuevo arte de gobernar, el derecho y las regulaciones normativas ocupan un lugar central en la formalización de la sociedad según el modelo de la empresa. La nueva gubernamentalidad neoliberal redefine la institución jurídica, las reglas del derecho, y el rol de los tribunales de justicia y arbitrales. En estas prácticas se imprimen las transformaciones del derecho internacional público, el surgimiento de los derechos humanos como nuevos universales y su institucionalidad en el período de la guerra fría. Si desde esta perspectiva sostenemos cómo hipótesis, que el desplazamiento de la lucha política hacía la lucha por el derecho, es un campo al que la propia gubernamentabilidad neoliberal desplazo la lucha política, por ello, a través de la judicialización de la política no se transforman las relaciones de poder, y se mantienen los modos actuales de apropiación y acumulación del capital. Entonces, nos proponemos analizar formas de resistencia a la judicialización de la política desde la propia acción política de los movimientos sociales, que aun utilizando el campo jurídico desplacen la lucha política al campo de la política, provocando la transformación de la institucionalidad jurídica como momento de esa praxis.
\end{abstract}

Palabras claves: derecho, judicialización de la política, vida campesina indígena, gubernamentabilidad neoliberal, lucha emancipatoria.

\section{ABSTRACT}

Starting from the theses developed by Michel Foucault regarding neoliberalism as a new art of governing, law and normative regulations occupy a central place in the formalization of society according to the model of the company. The new neoliberal governmentality redefines the legal

\footnotetext{
* Artículo recibido el 9 de enero de 2018; aceptado el 30 de marzo de 2018.

1 La autora es abogada (UNCu), Máster en Ciudadanía y Derechos Humanos, Ética y Política por la Universidad de Barcelona, Máster en Iniciació a la Recerca in Humanitats: Filosofía, Historia, Arte por la Universidad de Girona, y doctoranda en Ciudadanía y Derechos Humanos por la Universidad de Barcelona.
} 
institution, the rules of law, and the role of the courts of justice and arbitration. In these practices are printed the transformations of public international law, the emergence of human rights as new universals and their institutionality in the period of the cold war. If from this perspective we maintain a hypothesis, that the displacement of the political struggle toward the fight for the right, it is a field to which the neoliberal governability itself displaced the political struggle, for that reason, through the judicialization of politics they do not transform the power relations, and the current modes of appropriation and accumulation of capital are maintained. Then, we propose to analyze forms of resistance to the judicialization of politics from the political action of social movements, which even using the legal field to move the political struggle to the field of politics, causing the transformation of legal institutions as a time of that praxis.

Key words: Law, judicialization of politics, pesants indigenous life, neoliberal governability, emancipatory struggle.

"El creciente predominio del poder jurídico también debe entenderse en el contexto del debilitamiento de la esfera política democrática pública en la que debería tener lugar la confrontación agonística. Dada la creciente imposibilidad de concebir los problemas de la sociedad de una forma políticamente adecuada, existe una marcada tendencia a privilegiar el campo jurídico y a esperar que el derecho proporcione las soluciones a todos tipos de conflictos. La esfera jurídica se está convirtiendo en el terreno en el que los conflictos sociales encuentran su forma de expresión, y se considera que el sistema legal es responsable de organizar la coexistencia humana y de regular las relaciones sociales. Con el borramiento de la división entre la izquierda y la derecha, las sociedades liberales democráticas han perdido la capacidad de ordenar simbólicamente las relaciones sociales de forma política, e igualmente la capacidad de dar forma a las decisiones a las que han de hacer frente mediante discursos políticos". Chantal Mouffe. La paradoja democrática (pp. 127 y 128).

\section{La judicialización de la política}

El libro Justicia, política y derechos en América Latina (Palacio, Juan Manuel, Candioti, Magadalena, 2007), a través de diversos artículos analiza el fenómeno de la judicialización de la política, y el activismo judicial en Latinoamérica y el mundo. Así, Rodrigo Uprimny Yepes sostiene que la judicialización de la política es el fenómeno a través del cual, las cuestiones que antes se decidían a través de los medios políticos del juego de la democracia, empiezan a ser decididos por los jueces, o al menos esas decisiones se ven condicionadas por decisiones judiciales. Muchos actores sociales expresan sus demandas en términos jurídicos y judiciales (Palacio, Juan Manuel, Candioti, Magadalena, 2007, p. 46). Pilar Domingo señala que la judicialización de la política significa, en primer lugar, una mayor presencia de la actividad judicial en la vida política y social, los conflictos políticos, sociales o entre estado y sociedad, se resuelven cada vez más en los tribunales. En segundo lugar, diversos actores políticos y sociales ven ventajoso recurrir a los tribunales con el fin de proteger o promover sus intereses (Palacio, Juan Manuel, Candioti, Magadalena, 2007, p. 28).

El fenómeno estaría atravesado por la transformación de los diseños institucionales de los poderes judiciales, principalmente a través de las reformas constitucionales de la década del 
noventa, ${ }^{2}$ en que se crearon Cortes Constitucionales, mecanismos para la elección y designación de magistrados, límite temporal en la duración de estos cargos, la promoción de la independencia del Ministerio Público Fiscal. Asimismo, se incorporaron acciones colectivas para demandar por la vulneración de los derechos humanos, como el amparo, el habeas corpus, habeas data, acción de constitucionalidad, amparos ambientales, defensa del consumidor, etc.

En el mismo sentido, la mayoría de los libros que estudian el tema ${ }^{3}$ parten de la misma premisa: que la sociedad recurre más al poder judicial para reclamar el reconocimiento o efectivo goce de los derechos, judicialización desde abajo; que existen tribunales más activistas, judicialización desde arriba, o que los grupos hegemónicos, partidos políticos, utilizan los tribunales para mantener privilegios o disputar políticamente ciertos conflictos. En general, los abordajes están relacionados con los efectos que producen las sentencias judiciales, si perjudican la democracia, la división de poderes, si el poder judicial puede ejercer funciones de administración, si provoca movilización o desmovilización social. Es decir, tienden a mirar el fenómeno de la judicialización de la política sin preguntarse por sus causas o por qué, desde el regreso de las democracias se dan las luchas políticas en términos de derechos, y no de la política, por ejemplo, de disputa de los medios de producción.

En este trabajo indagaremos brevemente en las razones que habrían habilitado el fenómeno de la judicialización de la política, para luego, buscar las formas de resistencia a la gubernamentabilidad neoliberal. Para llevar a cabo esta tarea necesitamos esbozar una genealogía del discurso de los derechos humanos, y de la lucha política en el lenguaje del derecho y la judicialización de la política como práctica discursiva que permite y habilita relaciones y prácticas de poder. Desde allí, podremos igualmente pensar en prácticas contrahegemónicas que evidencien las fisuras, rupturas que ese discurso posibilita en las luchas de los pueblos. Cómo sostiene Foucault, no desde es el dominio de la revolución, tampoco del reformismo que tiene como función estabilizar el sistema de poder a través de cierto número de cambios, sino de la lucha por desestabilizar los mecanismos de poder.

\section{El imperialismo informal, y la gubernamentabilidad neoliberal}

\section{a) El lugar del derecho y los tribunales de justicia.}

En el orden neoliberal, el derecho como dispositivo de saber/poder, adquiere una nueva funcionalidad que describe Michel Foucault en el curso del College de France del año $1978 / 1979$, no ya desde la perspectiva de la teoría de la soberanía, las disciplinas, o las normas, sino en el marco de la sociedad regulada bajo la forma empresa.

En el período anterior, el derecho estaba centrado en lo social, en la población, en cómo sostener los periodos de la vida en que el trabajo no es posible, y en la eficacia de una proletarización creciente mediante dispositivos de formación, salud y familiarización, para mantener la tensión entre la acumulación del capital, el incremento de la renta, y la proletarización de la clase trabajadora. Entonces, el derecho se vinculaba con los dispositivos de gobernabilidad social proto-welfaristas (Benavente, 2015, p. 114-130).

\footnotetext{
${ }^{2}$ México 1994 y 1996, Colombia 1991, Ecuador 1998, Argentina 1994, Bolivia 1994, Paraguay 1992, Perú 1993 y Venezuela 1999.

${ }^{3}$ La judicialización de la política en América Latina, La revolución de los derechos, Juicio a la exclusión, Desde otra mirada. Apuntes de la teoría crítica, La Lucha por el derecho, entre otros.
} 
En los textos que analiza Foucault del año $1939^{4}$ los neoliberales alemanes y austríacos, sostenían en sus tesis la necesidad de superar los obstáculos que se habían presentado en la economía con el proteccionismo, el socialismo de Estado, la economía planificada y el dirigismo de tipo keynesiano. Un gobierno liberal debía ser activo, vigilante, interventor. Sin embargo, el problema no radicaba en la intervención misma, sino en su forma, en el estilo de gubernamentabilidad (Foucault, 2012, p. 135 y 137-139).

Estos teóricos sostenían la necesidad de que la libertad de mercado se constituyera como principio organizador y regulador del Estado, desde el comienzo de su existencia y hasta la última forma de sus intervenciones (Foucault, 2012: 149). Ello en cuanto, el capitalismo es la consecuencia de un diseño institucional y no de la lógica del capital, es un conjunto jurídico que se confunde con el sistema económico, al decir de Foucault, un conjunto de prácticas económicas reguladas. Por eso los economistas sostenían que debía crearse otro capitalismo, que intervenga en el conjunto de normas generales, en la estructura, a través del "intervencionismo jurídico", y del mínimo intervencionismo económico. Las leyes del mercado debían constituirse en el principio de la regulación general y social (Foucault, 2012, p. 199).

Debía aplicarse a la economía el imperio de la ley, no a través de un dejar hacer al mercado, sino a través de la regulación jurídica mediante las leyes del mercado, que permitieran constituir una nueva institucionalidad. De este modo, los estados no intervendrían políticamente en la economía, esta se desarrolla en un marco institucional jurídico que, en última instancia, se dirime en tribunales de justicia o arbitraje, y en principio se limitará a formalizar las reglas del juego económico, cuyos participantes son las empresas. Sólo podrá intervenir si ello está dispuesto en normas formales y generales. El capitalismo debe ser económico jurídico e institucional (Foucault, 2012, p. 206-216). El derecho desplaza a la política como principio ordenador de las relaciones de poder (Benavente, 2015, p. 115; Chantal, 2016).

El poder judicial tomará un nuevo rol y autonomía, no sólo aplican la ley general y formal, sino que dirimen todos los conflictos entre los sujetos de la gubernamentabilidad neoliberal, las empresas. Foucault cita a Rôpke "Ahora conviene hacer de los tribunales, mucho más que en el pasado, los órganos de la economía, y confiar a su decisión misiones que hasta hoy se asignaban a las autoridades administrativas." "En suma, en cuanto más formal es la ley, más amplia es la intervención judicial. $Y$ cuanto más se formalizan las intervenciones gubernamentales del poder público y más se retrocede la intervención administrativa, la justicia tiende a convertirse, y debe convertirse, en un servicio público omnipresente" (Foucault, 2012, p. 212).

Dezalay y Garth describen las transformaciones en el Banco Mundial en los años 90, con los dispositivos de poder que Foucault señalaba a fines de 1970, en cuanto, los economistas comenzaron a concentrarse más en el derecho, viendo en el mismo un aliado potencial que podía servir para la construcción de un mercado internacional de bienes y capital. El Banco Mundial en el Reporte mundial sobre desarrollo de 1991, "el desafío del desarrollo", le prestó mayor atención a las instituciones de gobierno y sus reformas, lo que incluía una atención especial a la necesidad de "crear nuevas estructuras jurídicas para el desarrollo del sector privado" (World Bank 1996, p. 88). Mediante las reformas institucionales, el Banco Mundial procuró introducir los derechos de propiedad, contratos, derecho empresarial y de inversión extranjera, derecho de concordatos y bancarrotas, derecho de la competencia, así como a la

\footnotetext{
${ }^{4}$ Coloquio de Walter Lippman realizado en Francia, principalmente Röpke, Rustow, Hayek, Von Mises.
} 
necesidad de un sistema judicial confiable y competente, y un ejercicio privado próspero de la profesión jurídica (World Bank, 1996, p. 88-93; Dezalay, 2005, p. 265).

Entonces, los economistas se centraron en el derecho para la construcción de un mercado internacional de bienes y capital, mediante la creación de nuevas estructuras jurídicas para los derechos de propiedad, empresarial, inversión extranjera, que debían ir acompañadas de un sistema judicial confiado y competente. (Dezalay, 2005, p. 265). Así, la gubernamentablidad neoliberal promovió las transformaciones ya señaladas en los poderes judiciales de los países periféricos, postguerra fría y postdictaduras.

Si se desplaza la intervención política de la economía por una intervención jurídica, los poderes judiciales serán protagonistas de la resolución de todos los conflictos originados en una sociedad económicamente regulada. Los conflictos sociales se transforman en jurídicos, y se dirimen en los tribunales.

Entonces, si la judicialización de todo conflicto o litigio originado en la multiplicación de los sujetos empresas se va desplegando por las distintas capas sociales; y dadas las reglas del juego que allí se utilizan, así como las relaciones de poder asimétricas que en ese campo se presentan; nos permiten proponer, que el desplazamiento de las luchas políticas hacia el campo del derecho y de lo judicial, es una consecuencia propia de la gubernamentabilidad neoliberal. Cómo señala Chantal Mouffe en La paradoja democrática se privilegia el campo jurídico para resolver los problemas políticos, esperando que el derecho proporcione las soluciones a los conflictos sociales, ya que el sistema legal es concebido como el responsable de organizar la coexistencia humana y regular las relaciones sociales (Chantal, 2016, p. 127 y 128).

\section{b) El derecho internacional público y el derecho internacional de los derechos humanos}

En este apartado, intentaremos describir brevemente la concreción de los dispositivos de poder del nuevo arte de gobernar neoliberal descripto por Michel Foucault, por un lado, en el proceso de consolidación del Derecho Internacional Público ${ }^{5}$ promovido por Estados Unidos, y el paradigma de los derechos humanos como parte de su política exterior en el marco de la guerra fría. Entre ellos, podemos mencionar igualmente la creación de los tribunales internacionales de derechos humanos, y del derecho comercial y empresarial.

La nueva institucionalidad de posguerra, ${ }^{6}$ la Organización de las Naciones Unidas, ${ }^{7}$ la OEA y la $\mathrm{CIDH}$ de acuerdo con el modelo estadounidense, fue posible en parte por lo que analiza Juan Pablo Scarfi en el Imperio de la ley (Scarfi, 2014), esto es, el imperialismo informal o legal promovido por Estados Unidos para toda América. El conjunto de ideas, principios, y teorías del DIP fue promovido a través de lugares claves de la política internacional, y de institutos académicos, en que destacados juristas ${ }^{8}$ vinculados a su gobierno desarrollaron la enseñanza, la discusión teórica, y la aplicación de sus principios para resolver los conflictos entre países de

\footnotetext{
${ }^{5}$ En adelante DIP.

6 También el FMI y el Banco Mundial.

7 En adelante ONU.

8 Principalmente de Brown Scott, consejero legal de Elihu Root, Secretario de Estado del gobierno de Theodore Rooselvet (1901-1909), quien influyó en la creación del Carnegie Endowment for International Peace (CEIP), y fundó la American Society of International Law (ASIL) y el American Journal Law(AJIL), organizaciones que nuclearon a un grupo de hombres del establishment estadounidense.
} 
América, originando la política de América para los americanos que se fundaba en su creciente interés geopolítico y económico en la región (Scarfi, 2014, p. 107).

Las ideas fuertes transmitidas como discurso de saber/poder se sintetizan en la resolución pacífica de los conflictos entre estados por medio del arbitraje, y ante todo por mecanismos judiciales, de las disputas internacionales y la organización internacional; y la creación de cortes de justicia internacionales, cuyo modelo era la Corte Suprema de Estados Unidos, que debían integrarse por jueces propuestos por los estados, imparciales y permanentes, para producir una doctrina y jurisprudencia internacional (Scarfi, 2014, p. 41 y 48).

Scarfi, señala la trascendencia del concepto de arbitraje entre estados a nivel internacional, como uno de los ejes del DIP, cómo nos indicaba Foucault. Las nuevas estructuras jurídicas para el desarrollo del sector privado, de carácter general y formal, que José Antonio Estévez describe como el «derecho corporativo global» (Estévez, 2016), establecen el arbitraje internacional cómo forma de resolución de conflictos, normas prescriptas en tratados de inversiones, de libre comercio, y transoceánicos.

Parte de este proceso lo constituye la Convención de Naciones Unidas sobre Ejecución de las Sentencias Arbitrales Extranjeras ${ }^{9}$ y el Convenio Sobre Arreglo de Diferencias Relativas a Inversiones entre Estados y Nacionales de Otros Estados, que en 1966 estableció que el Centro Internacional de Arreglo de Diferencias relativas a inversiones del Banco Mundial ${ }^{10}$ sea el fuero para resolver controversias entre inversionistas y Estados.

El derecho del arbitraje internacional se constituyó en un saber profesionalizado ostentado por las firmas de abogados de negocios, que en general, trasplantaron el modelo estadounidense. Así, se crearon en el sur facultades de derecho privadas promovidas por Estados Unidos, cuyos estudiantes realizan sus estudios de posgrado allí, y una vez egresados, litigan en el ámbito internacional, participan de negociaciones e instancias multilaterales, abogados que ocuparon un lugar destacado en los procesos de reestructuración y estatización de la deuda, y en las reformas de los estados periféricos de los períodos post dictatoriales. Por ejemplo, en la década del 90 en Argentina con el gobierno de Carlos Menem. Dezalay y Garth conceptualizan a esta norteamericanización de las técnicas y los conocimientos especializados como procesos de dolarización (Dezalay, 2005).

En los años 80, con la crisis de la deuda estás firmas de abogados de negocios ocuparon un lugar predominante en el dominio jurídico, en la reestructuración y estatización de la deuda, y en la construcción del andamiaje legal de las reformas de los estados y otras recetas de política neoliberal. Entonces, los "expertos", son preparados en las universidades del imperio para dar soluciones a las empresas trasnacionales en relación con los conflictos suscitados, principalmente, en las economías emergentes o débiles.

$\mathrm{Si}$, por un lado, el imperialismo informal a través del cual Estados Unidos colonizo el DIP y promovió la creación de la ONU, la OEA, y la Corte Interamericana de Derechos Humanos, y por otro, la gubernamentabilidad neoliberal ubico el campo judicial como el lugar donde resolver los conflictos de una sociedad económicamente regulada a través del derecho. Entonces, podemos inferir que, el surgimiento luego de la segunda guerra mundial y según el modelo estadounidense, de las declaraciones internacionales de Derechos Humanos, y las Cortes

\footnotetext{
${ }^{9}$ New York 1958.
}

${ }^{10}$ En adelante CIADI. 
Internacionales donde reclamar a los Estados por la violación de estos, se encuentran atravesadas por estas prácticas gubernamentales. Así, a través de la Declaración Universal en 1948 comienza a formalizarse el derecho internacional de los derechos humanos, y la modernidad como paradigma de racionalidad eurocéntrica, colonial e imperial, como forma ideal- esencialista de concebir los derechos y al ser humano (Lander, 2000, p. 22) alcanzarían un estado de institucionalidad internacional.

En el artículo "Poder y Derechos humanos en la Jurisprudencia de la Corte Interamericana. Una mirada crítica desde una nueva analítica de poder" (Benente [comp.], 2015), los autores analizan el límite de la CIDH respecto de sus sentencias. Refieren que la forma en que ella conceptualiza los derechos niega la posibilidad de modificar las relaciones de poder en las sociedades actuales. Señalan, entre sus principales debilidades, la referencia única del poder al Estado, reproducción de la teoría jurídica- política de la soberanía propia de los procesos de codificación. La CIDH desconoce de este modo, las múltiples formas e instituciones a través de las cuales el poder se ejerce.

Desde esta perspectiva podemos advertir que la Corte IDH en sus sentencias conceptualiza los derechos de tal modo que niega la posibilidad de modificar las relaciones de poder en las sociedades actuales, dada su única referencia del poder al estado, como reproducción de la teoría jurídica- política de la soberanía. El tribunal desconoce así las múltiples formas e instituciones a través de las cuales el poder se ejerce (Benavente, 2015, p. 160-185).

Entonces, si sólo el Estado puede violar derechos, sólo a él deberá exigírsele la realización de estos, su reconocimiento, resguardo o reparación. Al conceptualizar diversos derechos, individuales y sociales, en ningún caso se hace mención de las responsabilidades de los privados, de las empresas trasnacionales, obligando únicamente a los Estados a reparar las graves violaciones a los derechos humanos denunciados, ya que los capitales trasnacionales responden únicamente a través de la auto-regulación de los códigos de conducta (Estévez, 2016, p. 223-253). Aquí radica su principal límite. Proponen que la referencia conceptual de los derechos humanos debería estar atada a las relaciones de poder. Al invisibilizar las relaciones de poder, las mismas se reproducen y difícilmente se pueden transformar (Benente, [comp.] 2015, p. 160-185).

Por ello, resulta apropiado resaltar la paradoja que se presenta en el DIP cómo dispositivo de poder de la gubernamentabilidad neoliberal. Por un lado, respecto de la institucionalidad de los derechos humanos, los estados son los únicos responsables ante tribunales internacionales. Por otra parte, para demandar al estado por la pérdida de ganancias, e incumplimiento de algún tratado comercial, las empresas trasnacionales tienen subjetividad en el plano internacional, dada ésta por el nuevo marco legal, y pueden demandar a los estados en un plano de igualdad internacional ante el CIADI, en el marco de la Convención, y de los tratados de inversión.

Entonces, en un conflicto entre una comunidad indígena y una empresa transnacional por un territorio, el estado podrá ser demandado y condenado igualmente ante los tribunales internacionales de derechos humanos y de derecho empresarial con relación a ambas partes.

\section{c) Genealogía del discurso de los derechos humanos}

Por otra parte, y consolidando el imperialismo informal de Estados Unidos, en el marco de la guerra fría, emergió el discurso y la política de los derechos humanos, genealogía analizada por 
Yves Dezalay y Bryant Garth. ${ }^{11}$ Los derechos humanos y la ciencia económica neoliberal, nuevos universales, se encuentran atravesados por los procesos colonialistas que ha caracterizado al derecho en los países latinoamericanos siendo desplazado el predominio europeo por el estadounidense, luego de la segunda guerra mundial (Dezalay, 2005).

Luego de la segunda guerra mundial, la batalla contra el comunismo estuvo centrada en un principio en los países europeos y asiáticos, y en el plano jurídico se instrumentó en instituciones internacionales, fundaciones privadas (financiadas por la $\mathrm{ClA}^{12}$ ), agencias de estado de Estados Unidos, como la CIA, universidades prestigiosas, todas ellas controladas por la pequeña elite de abogados y funcionarios estadounidenses. Luego del triunfo de la Revolución Cubana en el año 1959, la política se dirigió hacia América Latina.

En los años 50 fue fundada, por abogados políticos estadounidenses de élite, diplomáticos, académicos, ministros, parlamentarios, magistrados de altos tribunales vinculados al Consejo de Relaciones Exteriores, la Comisión Internacional de Juristas (CIJ) radicada en Ginebra. Esta surgió, como respuesta y contraofensiva de la Asociación Internacional de Juristas Democráticos (AIJD) creada en 1946 por abogados franceses de izquierda con nexos en la Resistencia, y promovía la crítica realizada por los abogados expulsados de los países comunistas.

Igualmente, a través del Fondo Americano para los Juristas Libres (FAJL) perteneciente a la élite del gremio de abogados de Nueva York, se financiaba abogados de prestigio para la defensa del mundo libre, y fuertes convicciones anticomunistas. Hacia fines de los años 60, la Liga se afilió con la organización Freedom House con una orientación propia de la Guerra Fría, luego asumió una postura crítica contraria a las dictaduras de Chile y Paraguay.

La batalla contra el comunismo en el plano jurídico se instrumentó en distintos planos: instituciones internacionales, fundaciones privadas, agencias de estado de Estados Unidos, como la CIA, universidades prestigiosas, todas ellas controladas por la pequeña elite señalada precedentemente. No obstante, se buscó mostrar a las diversas entidades lo más autónomas e independientes posibles de la política exterior de los Estados Unidos. A pesar de ello, en el año 1967 se conoció que la CIJ era financiada secretamente por la CIA.

Este proceso de colonización respecto de los nuevos universales en el marco de la guerra fría, en un principio estuvo centrado en los países europeos y asiáticos influenciados por el comunismo. Luego del triunfo de la Revolución Cubana en el año 1959, la política se dirigió hacia América Latina, donde el proceso fue sumamente complejo y drástico, que presenta contradicciones y paradojas.

La lucha contra el comunismo, paralelamente a la promoción y difusión de los derechos humanos como nuevos universales, junto a la aplicación de las políticas neoliberales, se expresó en dictaduras sangrientas que se extendieron en América del Sur, todas ellas promovidas por la política internacional de Estados Unidos, y coordinadas entre sí en lo que se denominó el Plan Cóndor.

\footnotetext{
${ }^{11}$ Comisión Internacional de Juristas (CIJ) 1950, Fondo Americano para los Juristas Libres (FAJL) Freedom House, Fundación Ford,

${ }_{12}$ En el año 1967 se conoció la CIJ era financiada por la CIA y esto generó pedido de explicaciones en el Congreso de Estados Unidos y una discusión en torno a la política exterior de las organizaciones de derechos humanos.
} 
Durante la presidencia de John F. Kennedy, el gobierno tuvo un importante protagonismo en la lucha contra el comunismo a través de la política de la Alianza para el Progreso, y el rol ocupado por las fundaciones filantrópicas, fue asumido como política estatal. Por otra parte, a través de las agencias estatales como la CIA, se mantuvo la política de persecución a los movimientos de izquierda simpatizantes de Fidel Castro y la Revolución Cubana. Luego del asesinato de Kennedy en noviembre de 1963, predominó la política represiva sobre la de los amigos de América, profundizando las contradicciones propias de la estrategia hegemónica de Estados Unidos hacia América Latina.

El proceso de colonización, como señalan los autores, incluye también las propias contradicciones y luchas de poder en el seno de Estados Unidos. Por este motivo, puede entenderse, que la política y discurso de los derechos humanos permitieran enfrentar y deslegitimar las políticas de exterminio y persecución política llevadas a cabo por los regímenes militares, los que paralelamente eran promovidos y financiados por Estados Unidos.

La crítica a fundaciones filantrópicas por su vínculo con la CIA promovió un proceso de profesionalización de los derechos humanos ${ }^{13}$ creando centros de investigación que escudaban a intelectuales de izquierda amenazados por los regímenes militares, y programas generales que respaldaban universidades extranjeras (Dezalay, 2005, p. 104-116). En este marco, Amnisty Internacional ${ }^{14}$ procuró caracterizarse por su neutralidad, masividad y financiamiento de los propios activistas. Su legitimidad a nivel internacional se vincula a la resistencia a las dictaduras militares, especialmente, de Pinochet en Chile y Videla en Argentina.

Delazay y Garht demuestran a partir del recorrido de las distintas fundaciones y organizaciones de derechos humanos, ${ }^{15}$ de sus presidentes e integrantes, el proceso que transitaron desde la filantropía anticomunista de elite, hacia las gerencias financieras y profesionales incorporadas al mercado y la política, en la lógica de la gubernamentabilidad neoliberal. Ellas promovieron la creación de nuevas elites políticas en los países del tercer mundo y firmas de abogados de defensa de los intereses colectivos, pero igualmente de negocios, bajo los paradigmas de la racionalidad empresarial, como ya advertía Michel Foucault en el Nacimiento de la Biopolítica.

Los derechos humanos se transformarían en una carrera profesionalizada, cosmopolita, intelectual y política al que la elite jurídica estadounidense dedicaría sus esfuerzos económicos, técnicos, que formaría profesionales en las universidades más prestigiosas de dicho país ${ }^{16}$ (Dezalay, 2005, p. 255). Las propias agencias estatales e internacionales, como ejecutores de políticas públicas de la materia, necesitaron técnicos especialistas. Los organismos multilaterales, otorgaron protagonismo a las ONG al momento de tomar decisiones o diseñar inversiones estratégicas, en el marco del equilibrio economía de mercado-democracia y derechos humanos, lo que requería igualmente profesionales especializados.

Los procesos de dolarización se produjeron en el ámbito de los derechos humanos y de la economía. Por ello, paulatinamente se incorporaron a las prácticas locales, las técnicas y

\footnotetext{
${ }^{13}$ Por ejemplo, Human Righs Watch.

${ }^{14}$ Fundada en Inglaterra en 1961.

${ }^{15}$ Comisión Internacional de Juristas (CIJ) 1950, Fondo Americano para los Juristas Libres (FAJL) Freedom House, Fundación Ford.

${ }^{16}$ Por ejemplo, en la Universidad de Harvard.
} 
racionalidades desarrolladas en Estados Unidos, que tiene una larga trayectoria en activismo judicial respecto de derechos y libertades individuales desde que esto comenzaron a ser utilizados por las empresas a principios del siglo XX para discutir judicialmente los límites a la libertad de mercado impuestos por intervencionismo administrativo (Epp, 2013). En la década del 80, en ambas latitudes, los intereses colectivos fueron promovidos por ONGs de derechos humanos ${ }^{17}$, con centro en universidades de los Estados Unidos, así se convirtieron en actores claves en las transiciones hacia la democracia, y muchos abogados activistas formaron parte de los nuevos gobiernos (Dezalay, 2005, p. 92).

En las nuevas democracias de América del Sur, se desarrolló progresivamente una etapa de activismo judicial, al principio con acciones colectivas en resguardo de derechos y libertades civiles y políticos, y hacia la década del noventa, avanzada la aplicación de las políticas neoliberales, algunos organismos de derechos humanos emergentes en las dictaduras, y otros nuevos, darían la discusión jurídica del alcance de los derechos económicos, sociales y culturales a nivel nacional e internacional. La judicialización de la política se presentó en esta etapa, como expresión de la propia gubernamentabilidad neoliberal, interviniendo para asistir sólo a aquellos que lo necesitan (política negativa o de compensación).

Si bien este proceso de dolarización se interrumpió en los años 2000 con el ascenso a los gobiernos del cono sur de presidentes de centro izquierda, provenientes de los movimientos sociales o la militancia de los años setenta perseguida y encarcelada por los gobiernos militares, la judicialización de la política no se restringiría.

\section{En búsqueda de prácticas de resistencia: algunas precisiones sobre el uso del derecho en la defensa de la vida campesina}

Analizadas someramente las razones que habrían dado lugar al desplazamiento de la lucha política hacia la justicia como fenómeno de la gubernamentabilidad neoliberal, propondremos algunas rupturas o formas de resistencia en la lucha por la vida campesina en Argentina.

Es decir, si bien el discurso de los derechos humanos posibilita y habilita la expansión del neoliberalismo como nuevo arte de gobernar (la regulación mediante las reglas del mercado que garantiza a las empresas trasnacionales la apropiación de la vida a nivel mundial y que los estados funcionen como garantes de ello), también permite generar una ruptura a lo que se ese discurso viene a garantizar, y retornar al campo de la política lo que es propio de la política, la lucha por la vida.

En la lucha por la vida campesina del $\mathrm{MNCl}^{18}$ la judicialización de la política no se presenta cómo una práctica regular ni estratégica, sino más bien, cómo una acción de resistencia política y de supervivencia. En general, no lleva litigios estratégicos, ${ }^{19}$ sino que frente a los conflictos

\footnotetext{
17 Dado lo exiguo del trabajo no profundizaremos sobre el caso de los organismos de derechos humanos en Argentina que emergieron como resistencia a las dictaduras militares, Madres de Plaza de Mayo, Abuelas de Plaza de Mayo, MEDH, entre otros, cuyo trabajo estuvo más ligado a los procesos de lucha de Memoria, Verdad y Justicia, manteniendo la lucha en el campo de la política y su contenido.

${ }_{18}$ Movimiento Nacional Campesino Indígena.

${ }^{19}$ La única acción de estas características es una acción de amparo contra el estado nacional por la inconstitucionalidad del decreto 820/2016 que modifica la ley de extranjerización de la tierra.
} 
políticos (desalojos, desmontes) su dinámica, los conduce hacia el poder judicial a través de diversas estrategias para defender la vida campesina. ${ }^{20}$

Muchos movimientos no cuentan con abogados orgánicos, y tienen mucha dificultad para acceder a letrados que interpreten o se adecuen a su acción política, lo que torna más marginal el lugar que el derecho puede ocupar como acción política posible. Sumado a ello, la dinámica cotidiana de los conflictos, la urgencia para resolver lo inmediato, los escasos recursos económicos, tornan muy difícil que puedan desarrollar estrategias jurídicas más estructurales. Además, Argentina no cuenta con una Corte Constitucional a la que se puedan dirigir acciones de amparo o inconstitucionalidad y en cada caso, debe desarrollarse todo el proceso judicial desde la primera instancia, y resulta muy difícil acceder a la Corte Suprema de Justicia de la Nación que siente una jurisprudencia aplicable a todo el país.

En la lucha por la vida campesina, lo primero que ocurre es la criminalización por la defensa de los territorios, y la acción jurídica se dirige, cómo fue históricamente, a ejercer la defensa de los militantes en el ámbito penal ${ }^{21}$, la que debe ir acompañada de una acción que reconozca el derecho ejercido. Entonces, la defensa del territorio, condición material para la vida campesina, o vida digna, ejercida en la corporalidad viviente de las víctimas, esto es, "poner el cuerpo", parar una topadora, un desmonte, frenar un desalojo, constituye la acción política de los movimientos. A ella se sumarán las estrategias de comunicación, de articulación con otros sectores, de denuncia y de movilización, inclusive al poder judicial. La acción jurídica discutida políticamente acompañará todas las otras.

Es decir, la acción política procura responder a la judicialización de la política ejercida desde arriba a través de la criminalización de la defensa del territorio, y reforzar el triunfo de la política mediante la acción jurídica que declare el derecho vivido como legítimo. No son litigios estratégicos, en cuanto no son pensados cómo litigios primero, surgen con el conflicto. Son casos concretos, responden a la urgencia de la negación de la vida campesina. En estos casos, podríamos pensar que se construye nueva institucionalidad en términos de Dussel.

\footnotetext{
20 Por ejemplo, a través de amparos ambientales (causa Mamani Jujuy) acciones posesorias, habeas corpus, amparos individuales y colectivos, declaración de áreas campesinas, defensas y querellas penales. 21 Mendoza: $1^{\circ}$ Circunscripción Judicial: 82658/16 "Fs. c/Suarez Horacio p/turbación de la posesión"; 52.774/08 Fs. c/Quintero José Doril p/usurpación. 6 Fiscalía Correccional; 80.359/08 Fs. c/ Quintero, José Doril, Montón Diego, Guisasola Amalia p/turbación de la posesión, 28360/14 "Fs. c/Sarmiento Pablo, Sarmiento González Luis Facundo, Maturano Emilio, Bordón Ernesto, Sarmiento Víctor, Sarmiento Pablo Emilio, Quiroga Marcelo, y otros p/delito de turbación de la posesión en concurso ideal con amenazas coactivas agravadas por el uso de arma, en concurso real con daño. Fiscalía de delitos especiales; 15500/16 Fs. c/ Flores Beatriz p/usurpación, Fiscalía de Instrucción №33"; $2^{\circ}$ Circunscripción Judicial $71942 / 5$ "Fs.c/Villegas Roberto, Villegas Ariel, Villegas Julio, y Rojas Antonio p/delito de usurpación. $2^{\circ}$ Fiscalía Correccional; 932/8 "Fs. c/ Villegas, Luis, Villegas Roberto, Villegas Ariel, Villegas Julio, Arenas Aliberto, Mansilla Matías, Rojas Antonio, Rodriguez Elena, y ot. p/ usurpación p/ despojo", $2^{\circ}$ Fiscalía Penal de Menores; $3^{\circ}$ Circunscripción: $135126 / 12$ y 156248/12 Fs. c/Quintero Mario y otros p/delito de usurpación. Juzgado Federal de Dolores, FMP 20.727/2017 Fs. s/usurpación; 4 Circunscripción Judicial: 12341/16 Fs. c/Castillo Patricio, Castillo Dante y otro p/usurpación, Fiscalía Correccional de Tunuyan, Palma Sola, Jujuy: Expte. N²005/12, "Denuncia penal formulada por el Sr. Carlos Rene Bustamante con el patrocinio letrado del Dr. Fernando Daniel Barconte Ramos. Troncados en Paez, Rodolfo Gustavo p.s.a. Usurpación"; Causa №58/16 Canido Orlando c/ Raúl Lela y otros s/usurpación, Juzgado del Crimen de Primera Nominación de Santiago del Estero; causa N²0693/P2-58168/12.
} 
En estas acciones jurídicas, se discute políticamente el sentido del derecho, la política en cuanto ruptura, desacuerdo y litigio (Álvarez, 2013, p. 129-137), disputando de este modo la legalidad de lo que se vive cómo legítimo, pero que sin embargo, no se encuentra reconocido en las leyes positivas, por ejemplo, la posesión comunitaria de las comunidades campesinas, la propiedad comunitaria indígena (reconocida constitucionalmente pero no en los registros ni títulos), las formas de poseer el territorio en convivencia con los bienes naturales y no desde la perspectiva de la racionalidad capitalista, los medios de prueba, las propias acciones jurídicas, las limitaciones procesales, el derecho al monte nativo, a la soberanía alimentaria, a las semillas, en definitiva, a la vida campesina indígena.

EI MNCI dirige la lucha política en términos de derechos a los órganos clásicamente políticos, el poder legislativo y ejecutivo, y muy pocas veces al poder judicial. La constante enunciación de nuevos derechos, inclusive conquistando leyes, ordenanzas, ${ }^{22}$ declaraciones internacionales, no produce rupturas significativas en la Totalidad, sino solo en casos aislados de comunidades organizadas políticamente, que luego por la propia práctica gubernamental no se hace extensiva.

En Argentina, por ejemplo, en el año 2014 se sancionó la Ley n. ${ }^{\circ} 27.117$ de reparación histórica de la agricultura familiar, promovida por el MNCl. Dicha ley no se reglamentó, no es conocida, ninguna de sus disposiciones programáticas se ha cumplido. Por el contrario, desde el inicio del gobierno de Mauricio Macri, la Secretaría de Agricultura Familiar fue desmantelándose a través de despidos masivos de técnicos, eliminación de recursos, del Monotributo Social Agropecuario, entre otras. Algo muy similar ocurre con la ley de emergencia en materia de propiedad indígena 26.160, el INAI y los relevamientos territoriales. El pasado 28 de septiembre el Consejo de Derechos Humanos aprobó una Declaración de Derechos Campesinos y de otras personas que trabajan en las zonas rurales, promovida por la Vía Campesina Internacional, de la que el $\mathrm{MNCl}$ es parte. ${ }^{23}$

Las normas jurídicas conquistadas desde los movimientos adquieren vigencia, cuando los propios actores organizados pueden plantear su aplicación en los casos concretos luego de la defensa material de la vida campesina indígena. Así se ha logrado suspender desalojos aplicando la Ley 27.117 y 26.160 en juicios aislados, ${ }^{24}$ dónde las comunidades estaban organizadas. Sin embargo, su aplicación depende de las relaciones de poder concretas, pudiendo fallar el Poder Judicial contrariamente a todo el marco normativo.

Debemos destacar la creatividad en la defensa de los territorios campesinos para mantener la vida campesina, a través de la invención de Áreas Campesinas, superando los límites del derecho privado, y del derecho internacional de los derechos humanos, mediante la protección

\footnotetext{
22 Por ejemplo, en Jujuy la creación de Áreas Campesinas a través de ordenanzas municipales (AC), en Palpalá (Ordenanza n.․ 1156/2015) y Palma Sola (Ordenanza n.․153/CDPS/2016).

${ }^{23}$ La Vía Campesina es una organización mundial que disputa políticamente en todos los continentes los principios fundamentales de la globalización del capital, principalmente en su expresión del agronegocio. Más información en: https://viacampesina.org/es/.

https://viacampesina.org/es/la-via-campesina-el-consejo-de-derechos-humanos-de-las-naciones-unidasaprueba-la-resolucion-relativa-a-la-declaracion-sobre-los-derechos-de-las-y-los-campesinxs-en-ginebra/

${ }^{24}$ Se suspendió un desalojo en base a la Ley 27.117 en el Expte. n. ${ }^{\circ}$ 2005/12, "Denuncia penal formulada por el Sr. Carlos Rene Bustamante con el patrocinio letrado del Dr. Fernando Daniel Barconte Ramos Troncados en Paez, Rodolfo Gustavo p.s.a. Usurpación" Resolución de fecha 1/10/2015. Expte. FCB 7201616969/1996 "Banco de la Nación Argentina c/Robledo Eduardo p/ejecución hipotecaria. Juzgado Federal de la Rioja.
} 
de un espacio geográfico en cuanto allí viven familias campesinas, y no por los derechos individuales.

Así mediante la Ordenanza Municipal 153/2016 el 08 de septiembre de 2016 se Declaró Área Campesina el territorio comprendido en el departamento de Palma Sola, Provincia de Jujuy, que en su Art. 2 define al área campesina como un espacio geográfico con características socioambientales específicas, donde se territorializan los modos de vida de las familias campesinas. Estos territorios campesinos no son sólo materiales y funcionales, sino que también implican dimensiones simbólicas y culturales, donde se recrean prácticas, saberes y valores identitarios. En el Art. 3 señala el objetivo principal de la declaración, señalando que se busca el arraigo de las familias campesinas, fortaleciendo su modo de vida y producción, preservando fundamentalmente los recursos naturales existentes en ella (bosques nativos, agua, flora y fauna). La creación del área implica un ordenamiento territorial, ambiental y de tenencia de la tierra, el que se realizará de modo participativo e incluirá un censo de las familias campesinas que habitan el territorio comprendido en el área, relevándose los aspectos socio productivos, ambientales y de tenencia de la tierra (Art. 4 y 5 ).

Por otra parte, la ordenanza n. ${ }^{\circ} 1156 / 15$ del 04 de noviembre se declaró de Interés Municipal el área de Producción Periurbana de Agricultura Familiar de Palpalá y toda actividad pecuaria que allí se practique, definiendo en el Art. 2 el área cómo la parte de infraestructura verde del municipio constituida en forma espontánea, en la cual se promueve y fomenta la agricultura y ganadería familiar, y la protección del suelo a cargo de las familias que la habitan y se reconocen con una identidad común, se dispone igualmente realizar un censo de las familias en el territorio a fin de determinar la cantidad de familias poseedoras y las necesidades existentes, la autoridad de aplicación designada por el Municipio será la encargada de realizarlo garantizando la participación de las familias y las organizaciones (Art. 6 y 4). En el Art. 7 se establecen los objetivos de la norma, entre ellos, promover y fomentar la agricultura familiar periurbana y la protección de los suelos que han sido recuperados y aprovechados para la producción diversificada, amigable con el medioambiente que busca aportar alimentos sanos y productos orgánicos a la región; afianzar a la población en su territorio generando condiciones favorables en materia de hábitat, desarrollo productivo, y calidad de vida para la permanencia de las familias actuales y de las futuras generaciones; garantizar la provisión de servicios ambientales que las familias realizan (Art. 7).

Desde la perspectiva de la filosofía de la liberación, el derecho, sus normas, expresan la institucionalización de la praxis política emancipatoria de los movimientos sociales, que en función del fin de lo político (la producción, reproducción y aumento de la vida) va descubriendo nuevas necesidades, nuevos derechos, y lucha por su reconocimiento formal y material (las áreas constituyen un claro ejemplo). Es decir, las víctimas descubren su imposibilidad de vivir en algún nivel porque no puede satisfacer sus necesidades. Las víctimas sufren en su corporalidad viviente esta falta-de, en su aspecto formal como el no- derecho a. El derecho es un derecho vivido en la corporalidad viviente de las víctimas, como derecho a la reproducción de la vida campesina indígena, que emerge frente al desmonte, desalojo, a la privatización de las semillas, etc. El ejercicio de ese derecho, en el plano de lo material y no de lo enunciativo formal, es nueva legitimidad ilegal, la política como emancipación que puede devenir en nueva institucionalidad o no en la esfera formal o procedimental del nivel de las instituciones de la política de la liberación. 
El derecho y el poder judicial para los movimientos sociales son percibidos cómo el campo donde priman los derechos de los dominadores, de quienes no reconocen su derecho, no se escucha su voz y son criminalizados por defender sus territorios. El derecho penal totalmente selectivo, frente a las denuncias realizadas por las comunidades campesinas, indígenas, no promueve los procesos penales. Por el contrario, frente a una denuncia de un empresario, 0 quien pretende derechos sobre el territorio poseído por las comunidades, la justicia penal actúa e imputa los campesinos e indígenas, se los detiene, etc. La primera selectividad la realiza la policía, no tomando las denuncias, y actuando en general cuando los denunciantes son los titulares de dominio.

Dussel define los derechos humanos como resultado del proceso histórico de lo político, como el producto de la praxis política liberadora de las víctimas de cualquier sistema político, no exclusivamente del demoliberal occidental, y por ello, no sería coincidente con el proceso de institucionalidad de la gubernamentabilidad neoliberal descripto precedentemente.

En términos de Dussel, en el plano material, la reproducción de la vida para las comunidades campesinas e indígenas es inescindible al territorio, el agua, los bosques. Defender el territorio poseído desde una visión radicalmente distinta de la racional capitalista, sin tener títulos de dominio, son acciones políticas legítimas. Para los titulares registrales de las tierras, y principalmente para los operadores del sistema penal, estás prácticas son ilegales y constituyen acciones típicas del Código Penal. El cuerpo a cuerpo de esta lucha política, la capacidad de resistencia, movilización y discusión en la agenda pública serán determinantes para desplazarlas del lugar de la ilegalidad hacia el reconocimiento judicial del derecho.

\section{Conclusiones}

En este trabajo intentamos describir brevemente las prácticas de gubernamentabilidad neoliberal que habrían provocado el fenómeno de la judicialización de la política. Ello, con la finalidad de pensar críticamente sus límites y posibilidades.

Así advertimos cómo la emergencia de los derechos humanos como nuevos universales coincide con la institucionalidad de una nueva gubernamentabilidad en el período de posguerra, que buscaba desplazar la regulación política de la economía por el derecho, una sociedad regulada bajo las normas de la economía de mercado. Vimos cómo el diseño del DIP, los organismos internacionales y multilaterales, y las declaraciones universales, imperialismo informal de Estados Unidos hacia América y luego a nivel mundial, responde a ella.

Asimismo, intentamos buscar en la praxis política del M.N.C.I de Argentina, posibles formas de resistencia emancipadora en el uso del derecho. Ello, provocaría una ruptura en el desplazamiento de la lucha política hacia el derecho propia de la gubernamentabilidad neoliberal, ubicando a la lucha por la vida campesina en el campo de la política. 


\section{Referencias}

Álvarez, L. (2013). Derechos a la diferencia. El caso indígena en el discurso jurídico argentino. Buenos Aires: Biblos.

Benavente, M. (2015). Michel Foucault. Derecho y Poder. Lecturas sobre biopoder, gubernamentabilidad y derecho. Buenos Aires: Didot.

CELS. (2008). La lucha por el derecho. Buenos Aires: Siglo XXI.

Chantal, M. (2016). La paradoja democrática. Barcelona: Gedisa.

Courtis, C. (2009). Desde otra mirada. Textos de la Teoría Crítica. Buenos Aires: Eudeba.

Dezalay Yves, G. B. (2005). La internacionalización por las luchas del poder. La competencia entre abogados y economistas por transformar los países latinoamericanos. México: ILSA.UNAM.

Dussel, E. (2006). 20 Tesis de política. Madrid: Siglo XXI.

Epp, C. (2013). La Revolución de los Derechos. Abogados, activistas y cortes supremas en perspectiva comparada. Buenos Aires: Siglo XXI.

Estevez, J. A. (2016). La privatización de la regulación. Papeles de relaciones ecosociales y cambio global, $135,65 / 75$.

Ferrara, F. (2007). Los de la Tierra. De las Ligas Agrarias a los Movimientos Campesinos. Buenos Aires: Tinta Limón.

Foucault, M. (2012. 3 reimp.). Nacimiento de la biopolítica. Buenos Aires: Fondo de la Cultura Económica.

Herrera Flores, J. (2005). Los derechos humanos como productos culturales. Crítica del humanismo abstracto. Madrid: Los libros de la catarata.

Lander, E. (2000). La colonialidad del saber: eurocentrismo y ciencias sociales. Perspectivas latinoamericanas. Buenos Aires: Clacso.

Moyo, S. \& Yeros, P. (Coord.). (2008). Recuperando la tierra. El surgimiento de movimientos rurales en Africa, Asia y América Latina. Buenos Aires: Clacso.

Palacio, J. M. \&Candioti, M. (2007). Justicia, política y derechos en América Latina. Buenos Aires: Prometeo.

Rodríguez Garavito, C., \& Rodríguez Franco, D. (2015). Juicio a la exclusión. El impacto de los tribunales sobe los derechos sociales en el Sur Global. Buenos Aires: Siglo XXI.

Santos, B. de. (2009). Sociología Jurídica Crítica. Madrid: Trotta/Lisa.

Scarfi, J. P. (2014). El Imperio de la ley. Buenos Aires: FCE.

Sieder, R., Line, S., \& Alan, A. (2011). La Judicialización de la política en América Latina. México: CIESAS. Universidad Externado de Colombia.

Fuentes jurisprudenciales

-Sentencia n.. 450, 05/ 12/2006, autos caratulados: "Arévalo, Graciela del Valle y Otros c/ Julio Oscar Rodríguez y Otro Abreviado”, Juzgado Civil, Cruz del Eje, Provincia de Córdoba. Argentina.

-Autos n. ${ }^{\circ}$ 20649. "B.U.C.I. c/Querini, Armando p/Ejecución Hipotecaria" $1^{\circ}$ Juzgado Concursal de la $1^{\circ}$ Circunscripción Judicial de Mendoza. Argentina.

-Expediente n. ${ }^{\circ}$ 103.228, caratulado "Habeas Corpus preventivo a favor de Quintero José Doril". $2^{\circ}$ Juzgado de Garantías. $1^{\circ}$ Circunscripción Judicial de Mendoza. Argentina.

-Expediente n. B-229276-2010, caratulado: "Acción Colectiva de Amparo Ambiental Medida Cautelar Innovativa: Mamaní Agustín Pío y otros c/ Estado Provincial” -Dirección Provincial de Políticas Ambientales y Recursos Naturales- y la empresa CRAM S.A. Tribunal en lo Contencioso Jujuy. 
